\title{
Metoprolol Protects Against Arginine Vasopressin-Induced Cellular Senescence in H9C2 Cardiomyocytes by Regulating the Sirt1/p53/p21 Axis
}

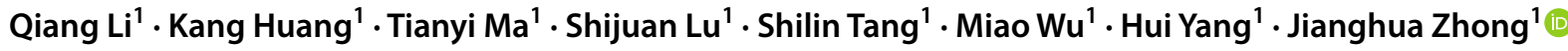

Received: 28 June 2021 / Accepted: 11 October 2021 / Published online: 20 November 2021

(c) The Author(s) 2021

\begin{abstract}
Cardiomyocyte senescence is involved in the pathological mechanism of cardiac diseases. Metoprolol is a $\beta 1$ receptor blocker used for the treatment of hypertension. Recent studies show that Metoprolol can protect cardiomyocytes against ischemia injury. The present study aims to investigate the protective effects of Metoprolol against arginine vasopressin (AVP)-induced cellular senescence in cultured cardiomyocytes. The cell proliferation assay and cytotoxicity lactate dehydrogenase assay showed that the highest tolerated dosage of Metoprolol in H9C2 cardiomyocytes was optimized as $10 \mu \mathrm{M}$. The enzymelinked immunosorbent assay showed that Metoprolol significantly ameliorated the elevated level of the DNA oxidation product 8-hydroxy-2 deoxyguanosine. Metoprolol also decreased the percentage of senescence-associated $\beta$-galactosidase positive cells and improved the telomerase activity under AVP exposure. Moreover, treatment with Metoprolol ameliorated the decreased intracellular nicotinamide phosphoribosyltransferase activity, nicotinamide adenine dinucleotide/nicotinamide adenine dinucleotide phosphate (NAD $/ \mathrm{NADPH}$ ) ratio, and Sirtuin1 activity in cardiomyocytes by AVP. Finally, Metoprolol was able to downregulate the AVP-induced expression of acetylated p53 and p21. Taken together, our data reveal that Metoprolol protected the cardiomyocytes from AVP-induced senescence.
\end{abstract}

Keywords Metoprolol $\cdot$ Cardiac hypertrophy $\cdot$ p53 $\cdot$ Cell senescence

\section{Introduction}

Pathological cardiac hypertrophy is a compensatory mechanism by which cardiomyocytes adapt to stress overload, which is a high risk for the pathogenesis of the decline of left ventricular function and chronic heart failure $[1,2]$. The clinical trials show that cardiac hypertrophy is the independent risk factor for disability and fatality rates induced by cardiac disease [3]. It is of high interest to patient care to investigate the underlying pathological mechanism of cardiac hypertrophy. Recent studies find that cardiomyocyte senescence is involved in the pathogenesis of pathological

Handling Editor: Y. Robert Li.

Jianghua Zhong

zhongjianghua07@163.com

1 Department of Cardiology, Haikou Affiliated Hospital of Central South University Xiangya School of Medicine, No. 43 Renmin Avenue, Meilan District, Haikou 570208, Hainan, China cardiac hypertrophy [4]. Cell senescence is a state of cellular proliferative arrest induced by several internal and external elements, such as oxidative stress and inflammation [5] and is mainly characterized by an increased cell size, promoted senescence-associated $\beta$-galactosidase (SA- $\beta$-gal) activity, and upregulated cyclin-dependent kinase inhibitors (CDKIs), such as p53, p21, and p16 [6, 7]. Compared to apoptosis, senescent cells maintain a certain metabolic activity and impact the surrounding microenvironment by secreting multiple types of growth factors, cytokines, inflammatory factors, and proteases, which are involved in the development and processing of embryo development, neurodegeneration, and malignant tumor $[8,9]$. It is reported that cell cycle arrest is observed in the majority of cardiomyocytes shortly after birth [10]. In the animal experiments, significant senescent characteristics were observed on the cardiomyocytes isolated from old mice, including elevated SA- $\beta$-gal activity, upregulated p53 and p21, accumulated lipofuscin, and declined telomerase activity [11, 12]. p53 is the vital transcriptional factor regulating the fate of the cell. p53-dependent control of p21 expression is one of the 
key pathways of cell growth arrest and genome integrity. The activation of these factors is the indication of cellular senescence [13]. Aging is reported to be an important element that induces cardiovascular diseases and cardiac hypertrophy is widely observed in the hearts of aged animals or human beings [12, 14]. In addition, similar characteristics are observed in cellular senescence and cardiac hypertrophy, such as the increased size of cardiomyocytes and activated synthesis of proteins $[15,16]$. Therefore, targeting the cell senescence in cardiomyocytes might be an effective method for the clinical treatment of pathological cardiac hypertrophy. Arginine vasopressin (AVP) is a hormone that regulates osmotic homeostasis and vasoconstriction in the cardiovascular system. The increased AVP concentration in plasma is positively associated with heart failure [17]. AVP-stimulated cardiomyocytes have been widely used as a cardiomyocyte hypertrophy model in vitro [18]. Metoprolol (Fig. 1) is a $\beta 1$ receptor blocker used for the clinical treatment of hypertension, stenocardia, and arrhythmia. It was developed by AstraZeneca and approved by the U.S Food and Drug Administration in 1975 [19]. By blocking the $\beta 1$ receptor located on the membranes of cardiomyocytes, Metoprolol opposes the excitatory effects at the cardiac level, thus decreasing blood pressure by lowering both heart rate and systolic output. With this anti-hypertensive property, it can also counterbalance an increase of the peripheral vascular resistance mainly dependent on the sympathetic innervation of small arterial myocytes [20]. Recently, Metoprolol showed significant protective effects on injured cardiomyocytes [21-24]. In the present study, we investigated the protective effect of Metoprolol against arginine vasopressininduced cell senescence to explore its potential therapeutic property of Metoprolol on pathological cardiac hypertrophy.

\section{Materials and Methods}

\section{Cell Culture and Treatments}

H9C2 cardiomyocytes were obtained from the Cell Bank of the Chinese Academy of Sciences (Shanghai, China) and cultured in Dulbecco's modified eagle medium (DMEM) supplemented with $10 \%$ fetal bovine serum (FBS) at $37{ }^{\circ} \mathrm{C}$

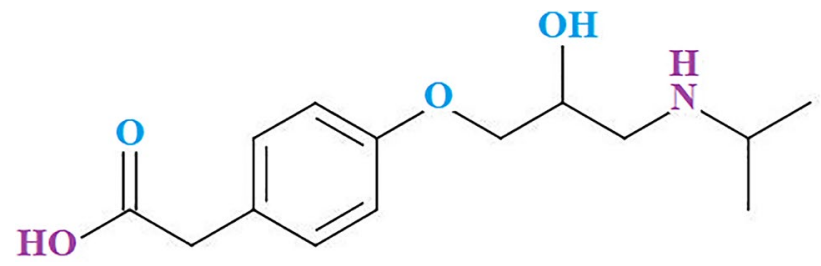

Fig. 1 Molecular structure of Metoprolol and 5\% $\mathrm{CO}_{2}$. To detect the cytotoxicity of Metoprolol in H9C 2 cardiomyocytes, cells were stimulated with $0.5,1,5$, $10,50,100$, and $500 \mu \mathrm{M}$ for $24 \mathrm{~h}$. To determine the protective effects of Metoprolol, cells were stimulated with AVP $(10 \mu \mathrm{M})$ in the presence or absence of Metoprolol $(5,10 \mu \mathrm{M})$ for $24 \mathrm{~h}$.

\section{Lactate Dehydrogenase (LDH) Release Assay}

Briefly, the treated $\mathrm{H} 9 \mathrm{C} 2$ cardiomyocytes were planted in a 96-well plate, followed by collecting the supernatant for LDH release assay. The supernatant was incubated with LDH reagents (Jiangcheng, Nanjing, China) for $1.5 \mathrm{~h}$, followed by detecting the absorbance at $450 \mathrm{~nm}$ using a BioRad 680 Microplate Reader.

\section{Cell Counting Kit-8 (CCK-8) Assay}

A CCK-8 assay kit (Jiangcheng, Nanjing, China) was used to detect the cell viability of $\mathrm{H} 9 \mathrm{C} 2$ cardiomyocytes treated with different strategies according to the instructions of the manufacturer. In brief, the cells were seeded in a 96-well plate followed by adding $10 \mu \mathrm{L}$ CCK-8 solution in each well. After incubation at $37^{\circ} \mathrm{C}$ for $3 \mathrm{~h}$, the absorbance at $450 \mathrm{~nm}$ was detected utilizing a PerkinElmer microplate reader (PerkinElmer, Massachusetts, USA).

\section{Enzyme-Linked Immunosorbent Assay (ELISA)}

The concentration of $8 \mathrm{OHdG}$ released by the treated $\mathrm{H} 9 \mathrm{C} 2$ cardiomyocytes was detected using ELISA assay. Briefly, the supernatants were collected following centrifugation and added to the 96-well plate. After removing the non-specific binding proteins by incubation with $1 \%$ bovine serum albumin (BSA) for $1 \mathrm{~h}$, the sample was supplemented with the primary antibodies and incubated at room temperature for $1 \mathrm{~h}$. Subsequently, the plates were washed with PBS buffer and added with streptavidin-horseradish peroxidase (HRP)conjugated secondary antibodies, followed by being incubated for $20 \mathrm{~min}$ at room temperature. Lastly, the microplate spectrophotometer (Thermo, Massachusetts, USA) was used to measure the absorbance at $450 \mathrm{~nm}$.

\section{SA- $\beta$-gal Staining Assay}

The treated $\mathrm{H} 9 \mathrm{C} 2$ cardiomyocytes were fixed with $2 \%$ formaldehyde and $0.2 \%$ glutaraldehyde for $10 \mathrm{~min}$ at room temperature and then washed using PBS buffer and SA- $\beta$-gal staining solution was added (Cell signaling Technologies, Massachusetts, USA), which consisted of $40 \mathrm{mM}$ citric acid/sodium phosphate ( $\mathrm{pH}$ 6.0), $150 \mathrm{mM} \mathrm{NaCl}, 2 \mathrm{mM} \mathrm{MgCl} 2,5 \mathrm{mM}$ potassium ferrocyanide, $5 \mathrm{mM}$ potassium ferricyanide, and $1 \mathrm{mg} / \mathrm{mL}$ of 
5-bromo-4-chloro-3-indoyl- $\beta$-D-galactopyranoside. After incubation at $37{ }^{\circ} \mathrm{C}$ for $16 \mathrm{~h}$, the percentage of SA- $\beta$-galpositive cardiomyocytes was calculated under a microscope (Olympus, Tokyo, Japan).

\section{Telomerase Activity}

After lysing the treated H9C2 cardiomyocytes using RIPA lysis buffer (Beyotime, Shanghai, China), the supernatant was collected after centrifugation. The telomerase activity was detected utilizing the telomerase ELISA kit (Mlbio, Shanghai, China) according to the description reported previously [25].

\section{iNampt Activity}

The iNampt activity in the cardiomyocytes was detected using the NAMPT Activity Assay kit (Abcam, Cambridge, UK) according to the instructions of the manufacturer. In brief, the lysis of the treated H9C2 cardiomyocytes was mixed with two-step reaction mix 1 and incubated for $60 \mathrm{~min}$ at $30{ }^{\circ} \mathrm{C}$. After adding the two-step reaction mix 2 , the samples were incubated for $30 \mathrm{~min}$ at $30{ }^{\circ} \mathrm{C}$. Lastly, the absorbance at $450 \mathrm{~nm}$ was detected using the PerkinElmer microplate reader (PerkinElmer, Massachusetts, USA).

\section{Measurement of $\mathrm{NAD}^{+} / \mathrm{NADPH}$ Ratio}

The NAD ${ }^{+} / \mathrm{NADPH}$ quantification kit (Bio Vision, San Francisco, USA) was used to detect the cellular concentration of $\mathrm{NAD}^{+}$according to the instructions of the manufacturer. Using the commercial kit, the concentrations of $\mathrm{NAD}^{+}$ and NADPH were detected based on an enzyme cycling reaction, a sensitive method for the measurement of $\mathrm{NAD}^{+}$ and NADPH levels.

\section{Sirt1 Activity}

The cardiomyocytes were homogenized in lysis buffer containing Tris- $\mathrm{HCl}, \mathrm{NaCl}$, phenylmethylsulfonyl fluoride, leupeptin, and aprotinin and then the total proteins were collected after centrifugation for $10 \mathrm{~min}$ at 15,000 rpm and $4{ }^{\circ} \mathrm{C}$. The histone deacetylase colorimetric assay kit (Enzo Life Science, New York, USA) was utilized to detect the Sirt1 activity according to the instructions of the manufacturer.

\section{Immunoprecipitation of Acetylated p53}

Cardiomyocytes were lysed and the protein concentration was evaluated using the bicinchoninic acid (BCA) method. $1 \mathrm{mg}$ total protein was mixed with $5 \mu \mathrm{g}$ anti-acetylated-lysine antibody (CST, Massachusetts, USA) and incubated at $4{ }^{\circ} \mathrm{C}$ overnight to form an antigen-antibody complex. $50 \mu \mathrm{L}$ magnetic beads were then added to the complex solution and incubated at $4{ }^{\circ} \mathrm{C}$ for $4 \mathrm{~h}$. After centrifugation by $2500 \mathrm{rmp}$ at $4{ }^{\circ} \mathrm{C}$, the complex was collected and stored at $-80^{\circ} \mathrm{C}$ for subsequent western blot analysis using p53 antibody.

\section{Real-Time PCR Assay}

The total RNA was isolated from the treated cardiomyocytes using the Trizol reagents (Thermo, Massachusetts, USA). The extracted RNA was treated with DNase I (Thermo, Massachusetts, USA) for 10 min to remove contaminated cDNA. The quality and concentration of RNA were validated using a Nanodrop 2000 spectrophotometer (Thermo, Massachusetts, USA). The wavelength absorption ratio (260/280 nm) was between 1.8 and 2.0 for all preparations. A total $1 \mu \mathrm{g}$ of RNA was transcribed into cDNA utilizing the Reliance Select cDNA Synthesis Kit (Bio-Rad, California, USA). In the present study, the PCR reaction was conducted utilizing the SYBR Master Mix kit with a $25-\mu \mathrm{L}$ reaction system and the StepOne-Plus system (Takara, Tokyo, Japan) according to the following procedure: denaturing at $95{ }^{\circ} \mathrm{C}$ for $30 \mathrm{~s}$, annealing at $60{ }^{\circ} \mathrm{C}$ for $1 \mathrm{~min}$ and extending at $95{ }^{\circ} \mathrm{C}$ for $5 \mathrm{~s}$ for 40 cycles, and $72{ }^{\circ} \mathrm{C} 10 \mathrm{~min}, 1$ cycle. Finally, the $2^{-\Delta \Delta \mathrm{Ct}}$ method was used to determine the relative expression level of target genes with $\beta$-actin used for normalization. The following primers were used in this study: p21, (F: 5' -TGTTCC ACACAGGAGCAAAG-3', R: 5'-AACACGCTCCCAGAC GTAGT-3'), $\beta$-actin (F: 5'-CTGCCCTGGCTCCTAGCA C-3', R: 5'- CGGACGCAGCTCAGTAACAGTCCG-3').

\section{Western Blot Assay}

After extracting the total proteins from the treated cardiomyocytes with the RIPA Lysis Buffer (Beyotime, Shanghai, China), the proteins were quantified with a BCA kit (Beyotime, Shanghai, China), followed by being loaded and separated by the SDS-PAGE. Then, the separated proteins were transferred to the PVDF membranes (Beyotime, Shanghai, China), followed by incubation with 5\% BSA for the removal of non-specific binding proteins. Subsequently, the membrane was incubated with the primary antibody against p53 (1:1000, CST, Massachusetts, USA), p21 (1:1000, CST, Massachusetts, USA), and $\beta$-actin (1:1000, Massachusetts, Boston, USA) at $4{ }^{\circ} \mathrm{C}$ overnight, followed by being incubated with secondary antibody at room temperature for $1.5 \mathrm{~h}$. Finally, the membrane was incubated with ECL solution (Beyotime, Shanghai, China) and then exposed to Tanon 5200-multi (Tanon, Shanghai, China). ImageJ software was used to quantify the relative expression level of target proteins. 


\section{Data Analysis and Statistical Methods}

Data are expressed as mean \pm standard errors (S.E.). Statistical analysis was performed using the software SPSS 22.0. All data were tested for normal distribution using the Shapiro-Wilk test. Data with normal distributions were compared using a two-way analysis of variance (ANOVA) followed by a Tukey's post hoc test. Nonparametric data were analyzed with the Kruskal-Wallis H test. $P<0.05$ was considered statistically significant.

\section{Results}

\section{Cytotoxicity of Metoprolol in H9C2 Cardiomyocytes}

To obtain the optimized concentration of Metoprolol for the treatment of $\mathrm{H} 9 \mathrm{C} 2$ cardiomyocytes, cells were stimulated with $0.5,1,5,10,50,100$, and $500 \mu \mathrm{M}$ for $24 \mathrm{~h}$ followed by detecting cytotoxicity using CCK-8 assay and LDH release assays. As shown in Fig. 2A, as the concentration of Metoprolol increased from 0.5 to $10 \mu \mathrm{M}$, the $\mathrm{LDH}$ release was maintained around 5\%, which was then significantly elevated as the concentration of Metoprolol increased to $50 \mu \mathrm{M}$. In addition, compared to the control, as the concentration of Metoprolol increased from 0.5 to $10 \mu \mathrm{M}$, no significance was observed on the cell viability of the $\mathrm{H} 9 \mathrm{C} 2$ cardiomyocytes. It was later dramatically declined to $92.1 \%, 85.3 \%$, and $76.9 \%$ by the treatment with 50,100 , and $500 \mu \mathrm{M}$ Metoprolol, respectively (Fig. 2B). Therefore, in the subsequent experiments, 5 and $10 \mu \mathrm{M}$ Metoprolol were used.

\section{Metoprolol Ameliorated Arginine Vasopressin (AVP)-Induced Oxidative Stress in $\mathrm{H9C2}$ Cardiomyocytes}

As shown in Fig. 3, compared to the control group, the level of $8 \mathrm{OHdG}$ was elevated from 3.2 to $7.1 \mathrm{pg} / \mu \mathrm{g}$ DNA by stimulation with AVP. It was then suppressed to 5.3 and $4.3 \mathrm{pg} / \mu \mathrm{g}$ DNA by treatment with 5 and $10 \mu \mathrm{M}$

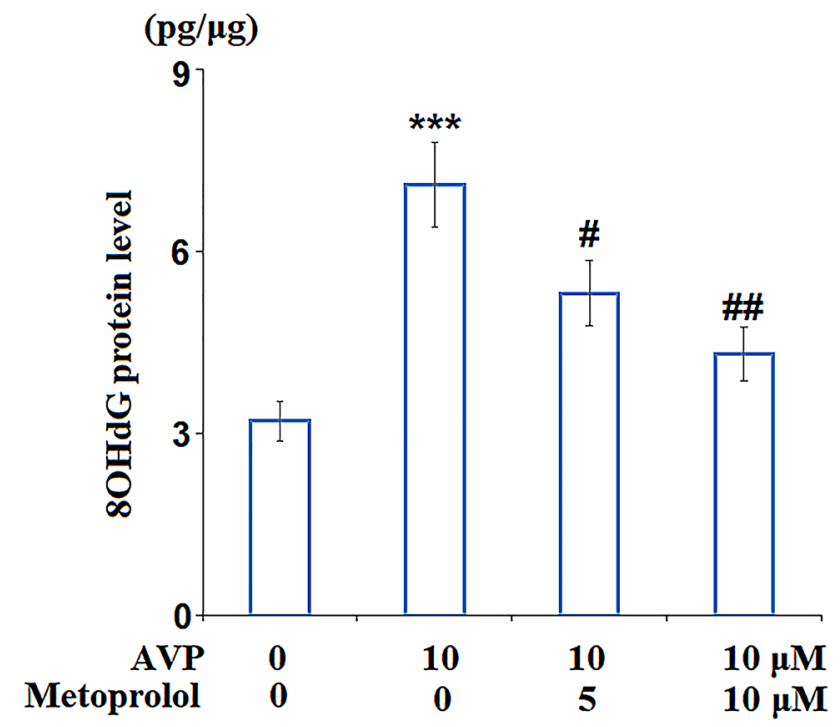

Fig. 3 Metoprolol ameliorated arginine vasopressin (AVP)-induced oxidative stress in $\mathrm{H} 9 \mathrm{C} 2$ cardiomyocytes. Cells were stimulated with AVP $(10 \mu \mathrm{M})$ in the presence or absence of Metoprolol (5, $10 \mu \mathrm{M})$ for $24 \mathrm{~h}$. Levels of $8 \mathrm{OHdG}$ were measured using ELISA (*** $P<0.005$ vs. control; \#, \#\#P<0.05, 0.01 vs. AVP group, $n=5-6$ )

Metoprolol, respectively, indicating the oxidative stress in cardiomyocytes induced by AVP was significantly ameliorated by Metoprolol.

\section{Metoprolol Ameliorated AVP-Induced Cell Senescence}

We further investigated the impact of Metoprolol on cell senescence in AVP-challenged cells. Representative SA- $\beta$ gal staining results are shown in Fig. 4A. The percentage of SA- $\beta$-gal-positive cells was significantly elevated by stimulation with AVP. Interestingly, the introduction of Metoprolol dose-dependently decreased this percentage (Fig. 4B), indicating that the cell senescence induced by AVP was significantly alleviated by Metoprolol.
Fig. 2 Cytotoxicity of Metoprolol in $\mathrm{H} 9 \mathrm{C} 2$ cardiomyocytes. Cells were stimulated with 0.5 , $1,5,10,50,100$, and $500 \mu \mathrm{M}$ for $24 \mathrm{~h}$. A LDH release; B cell viability $(*, * *, * * * P<0.05$,

$0.01,0.005$ vs. control, $n=5-6$ )
(A)

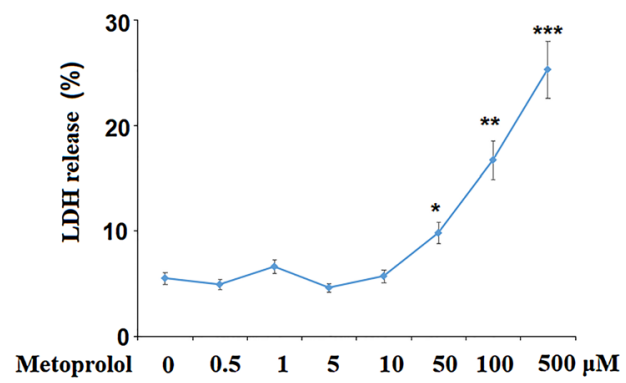

(B)

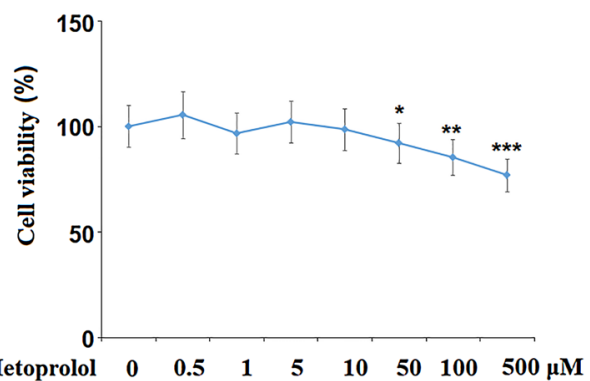


Fig. 4 Metoprolol ameliorated arginine vasopressin (AVP)induced cell senescence. Cells were stimulated with AVP $(10 \mu \mathrm{M})$ in the presence or absence of Metoprolol for 7 days. A Senescence-associated beta-galactosidase (SA- $\beta$ gal) staining; $\mathbf{B}$ quantification of SA- $\beta$-gal activity $(* * * P<0.005$ vs. control; \#, \#\#P<0.05, 0.01 vs. AVP group, $n=5-6$ )

(A)

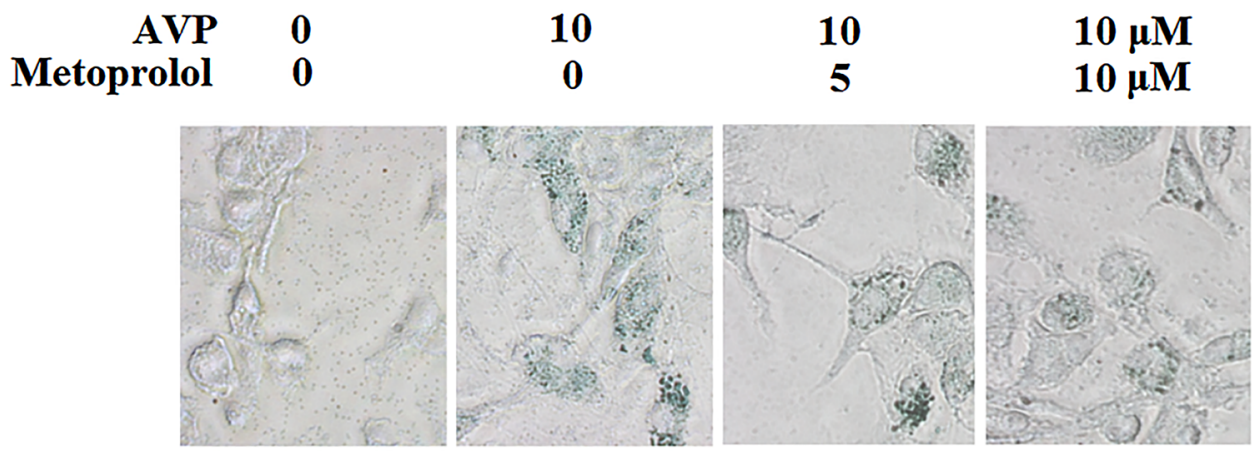

(B)

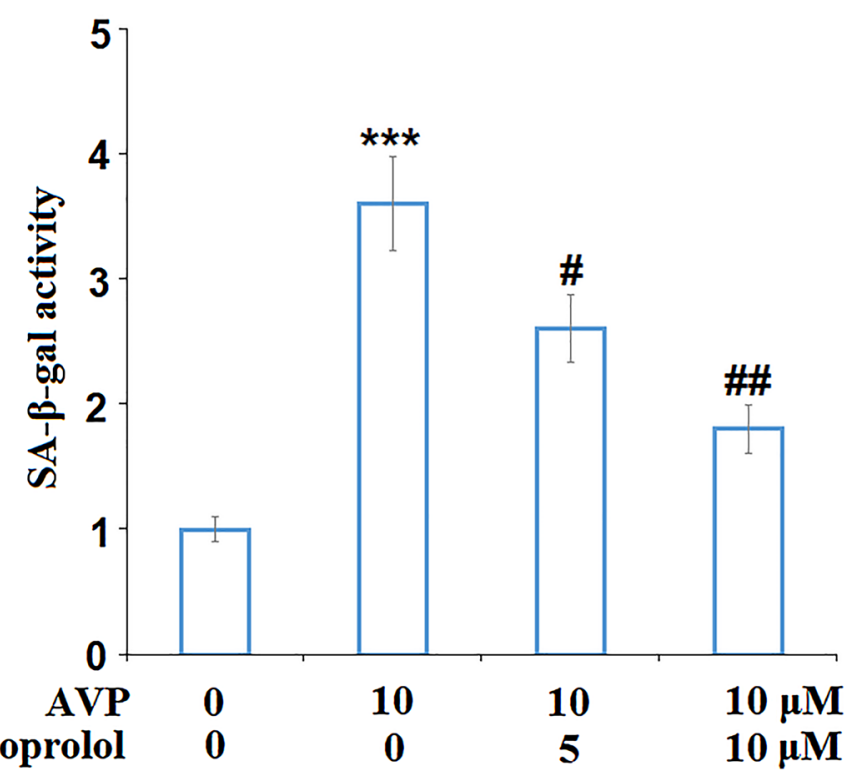

\section{Metoprolol Ameliorated AVP-Induced Decrease in Telomerase Activity}

Cells were stimulated with AVP $(10 \mu \mathrm{M})$ in the presence or absence of Metoprolol (5 and $10 \mu \mathrm{M})$ for 7 days. As shown in Fig. 5, compared to the control group, the telomerase activity was decreased from 29.5 to $17.8 \mathrm{IU} / \mathrm{L}$ by the stimulation with AVP but pronouncedly elevated to 23.6 and $27.1 \mathrm{IU} / \mathrm{L}$ by the introduction of Metoprolol in a dosedependent manner.

\section{Metoprolol Rescued AVP-Induced Dysfunction in the iNampt-NAD ${ }^{+}-$SIRT1 System}

To explore the effects of Metoprolol on the normal function of cardiomyocytes, cells were stimulated with AVP $(10 \mu \mathrm{M})$ in the presence or absence of Metoprolol (5 and $10 \mu \mathrm{M}$ ) for $24 \mathrm{~h}$, and the iNampt activity, NAD $/ \mathrm{NADPH}$ ratio, and Sirt1 activity were examined using commercial kits. As shown in Fig. 6A-C, compared to the control,

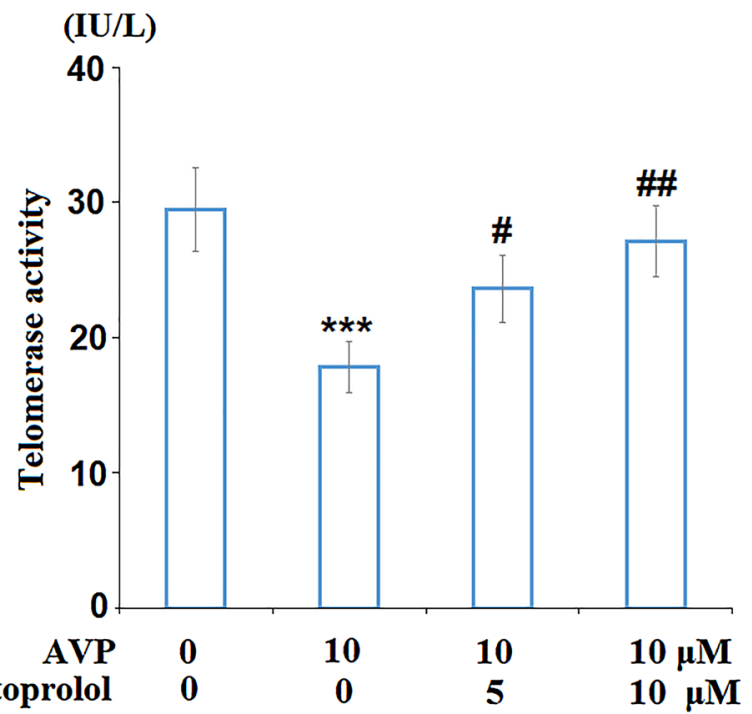

Fig. 5 Metoprolol ameliorated arginine vasopressin (AVP)-induced decrease in telomerase activity. Cells were stimulated with AVP $(10 \mu \mathrm{M})$ in the presence or absence of Metoprolol for 7 days. Telomerase activity was assessed (*** $P<0.005$ vs. control; \#, \#\#P<0.05, 0.01 vs. AVP group, $n=5-6$ ) 
Fig. 6 Metoprolol rescued Arginine vasopressin (AVP)-induced dysfunction in the iNampt-NAD ${ }^{+}-\mathrm{SIRT} 1$ system. Cells were stimulated with AVP $(10 \mu \mathrm{M})$ in the presence or absence of Metoprolol for $24 \mathrm{~h}$. A iNampt activity; B NAD ${ }^{+} / \mathrm{NADPH}$ ratio; C Sirt1 activity (*** $P<0.005$ vs. control; \#, \#\#P<0.05, 0.01 vs. AVP group, $n=5-6$ )

AVP suppressed the iNampt activity, $\mathrm{NAD}^{+} / \mathrm{NADPH}$ ratio, and Sirt1 activity, all of which were elevated by treatment with Metoprolol in a dose-dependent manner.

\section{Metoprolol Mitigated AVP-Induced Increase in Acetylation of p53 and the Expression of p21}

CDKIs, such as p53 and p21, are important biomarkers of cell senescence, the expression levels of which were detected following the treatments. Sirt 1 acts as an inhibitor of p53 acetylation. Interestingly, we found that the upregulated acetylated p53 in the AVP group was significantly downregulated by the introduction of Metoprolol (Fig. 7A). In addition, as shown in Fig. 7B, C, compared to the control group, AVP significantly promoted the expression level of $\mathrm{p} 21$, which was then inhibited by treatment with Metoprolol in a dose-dependent manner at both the mRNA and protein levels.

\section{Discussion}

Cell senescence is observed in the cardiac hypertrophy model induced by angiotensin II and in dilated cardiomyopathy caused by the silencing of Bmi1, which is verified by the elevated proportion of SA- $\beta$-gal-positive cells [26]. Oxidative stress is an important inducer for cell senescence [27]. The production of reactive oxygen species (ROS) is involved in cardiac remodeling following isoproterenol injection, including wall stiffness and fibrogenesis $[28,29]$. In addition, the inhibition of myocyte autophagy was observed in cardiac hypertrophy, proven to be closely related to the activation of oxidative stress [30, 31]. The accumulation of lipofuscin is induced by the activated oxidative stress and suppressed autophagy, which is believed to be an important inducer for cardiac dysfunction in aged rats $[11,12]$. AVP is a nonapeptide secreted by the posterior pituitary gland and hypothalamus. It stimulates vasoconstriction by regulating the function of the adenosine triphosphate-sensitive potassium channel and inducing the production of nitric oxide [32], which is proven to be closely related to the development of heart failure [33, 34]. In the present study, AVP was used to induce the in vitro
(A)

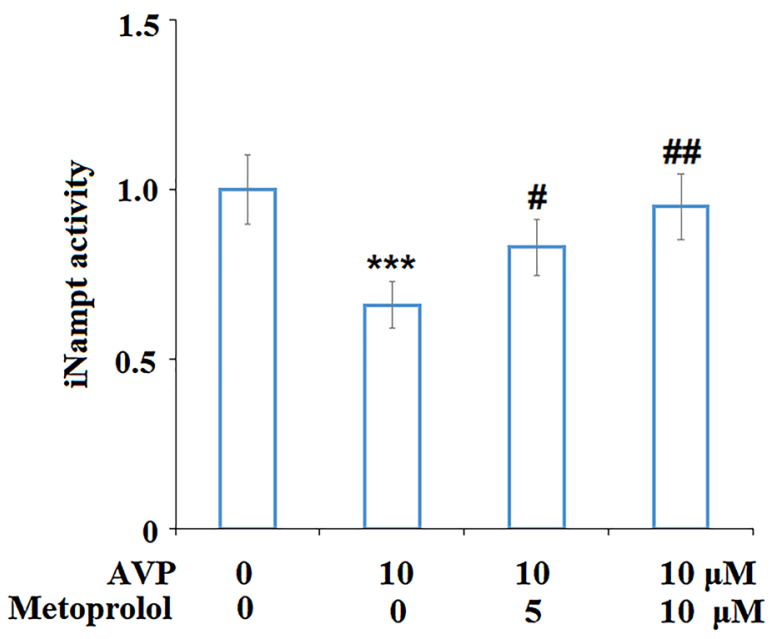

(B)

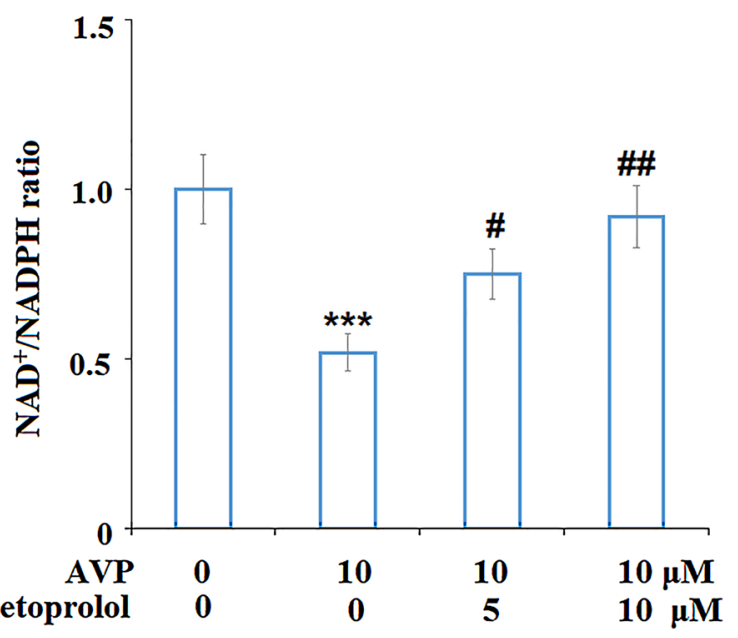

(C)

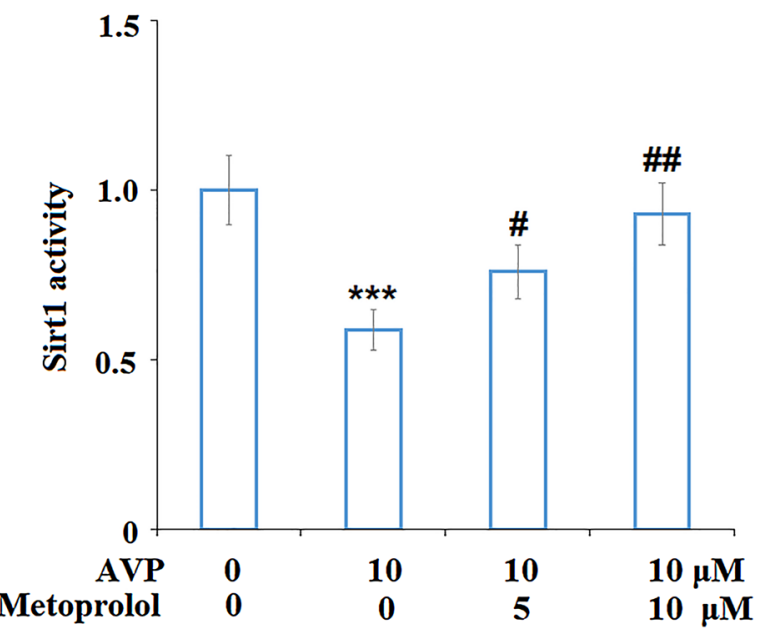


Fig.7 Metoprolol mitigated Arginine vasopressin (AVP)-induced increase in acetylation of p53 and the expression of p21. Cells were stimulated with AVP $(10 \mu \mathrm{M})$ in the presence or absence of Metoprolol for $24 \mathrm{~h}$. A Levels of acetylated p53 were measured with immunoprecipitation; $\mathbf{B}$ mRNA of $\mathrm{p} 21$; $\mathbf{C}$ protein of $\mathrm{p} 21(* * * P<0.005$ vs. control; \#, \#\#P<0.05, 0.01 vs. AVP group, $n=5$ )

injury model on cardiomyocytes, which was verified by the activated oxidative stress and aggravated cell senescence. The state of oxidative stress and cell senescence were dramatically alleviated by treatment with Metoprolol, indicating its protective effect on the injury of cardiomyocytes induced by AVP. In our future work, more evidence will be provided to further confirm the protective effects of Metoprolol, such as detecting the level of mitochondrial ROS, measuring the production of inflammatory factors, and determining the activity of superoxide dismutase (SOD).

Sirtuin 1 (Sirt1) is reported to be a NAD ${ }^{+}$-dependent deacetylase and plays an important role in regulating cell senescence, apoptosis, and the cell cycle by mediating the acetylation of several transcriptional factors, including p53, FOXO, and histones $[35,36]$. It is reported that the concentration of $\mathrm{NAD}^{+}$could be inhibited by the activation of nicotinamide phosphoribosyltransferase (iNampt), which is a rate-limiting enzyme for the synthesis of $\mathrm{NAD}^{+}$ and it inhibits the activity of Sirt1 [37, 38]. Therefore, Sirt1 is an important regulatory transcriptional factor that negatively regulates the development and processing of cell senescence induced by oxidative stress [39] by deacetylating p53. In the present study, we found that Metoprolol rescued the significantly reduced activities of Sirt1 and iNampt, as well as the concentration of NAD by AVP. These data verify the protective effects of Metoprolol on the AVP-induced cell senescence in cardiomyocytes.

Protein p53 is a tumor suppressor comprised of 393 amino acids and is an important transcriptional factor that regulates the cell cycle, cell senescence, and apoptosis. Its upregulation induces cardiomyocytes cell death by suppressing the angiogenesis in the heart tissues and its silencing of p53 is reported to alleviate the heart function [40]. Acetylated p53 plays an important role in mediating the expression of its downstream genes such as $\mathrm{p} 21$.

Our data show that AVP suppressed SIRT-1 activity and increased acetylated p53 and released p 21 expression. The acetylation of p53 and its induction on its downstream target $\mathrm{p} 21$ has been shown to contribute to genomic instability and cellular senescence [41]. In the cardiovascular system, SIRT-1/p53 has been shown to modulate cardiovascular aging [42]. In our experiment, AVP treatment reduced iNampt activity, which is the rate-limiting enzyme in the process of NAD + production. As a result,
(A)
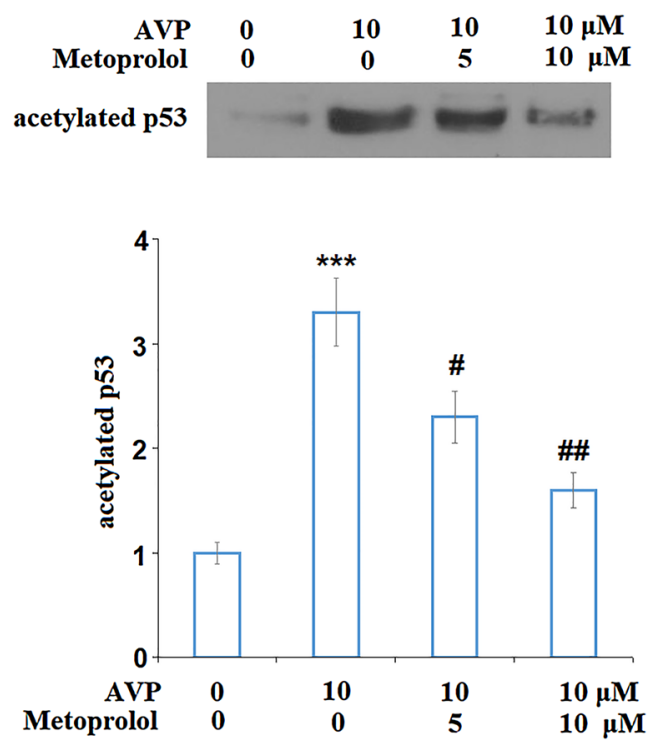

(B)

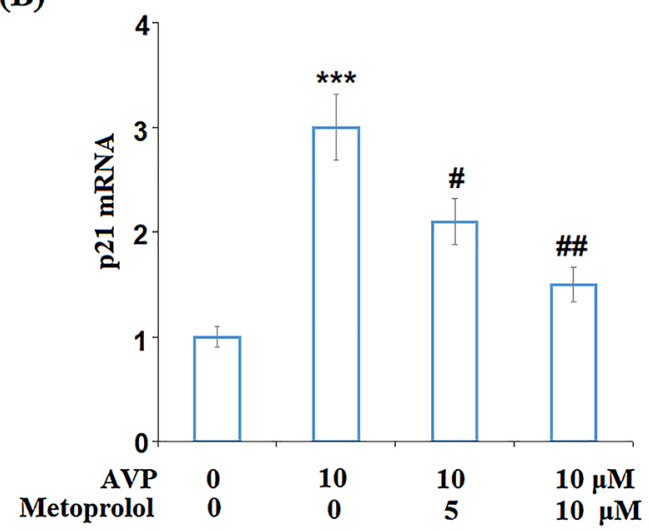

(C)

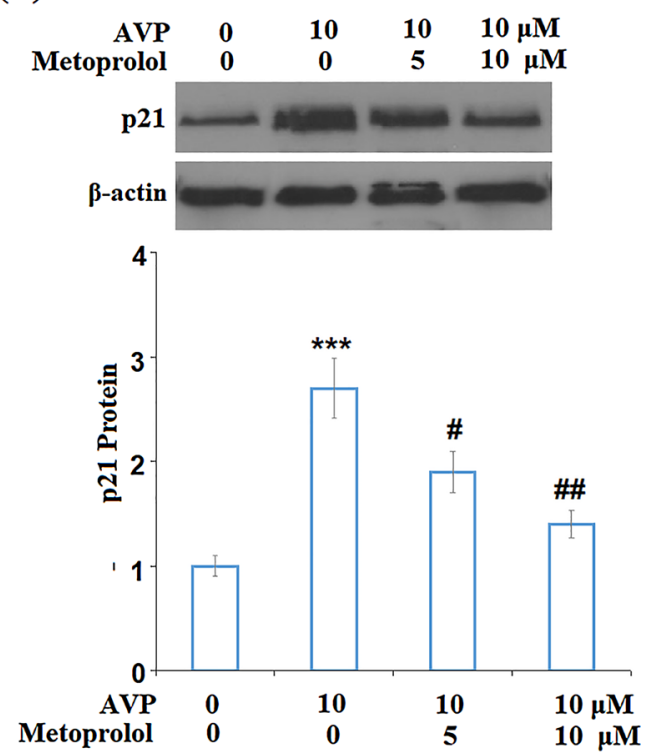


cellular NAD +/NADPH was reduced (Fig. 6B). SIRT-1 is an NAD +-dependent deacetylase, and its activity was decreased when the availability of NAD + was reduced (Fig. 6C). However, the addition of Metoprolol ameliorated AVP-elicited effects. Therefore, the action of Metoprolol on the NAD + pathway could be responsible for its effect on SIRT-1/p53.

In summary, our data demonstrate the protective effects of Metoprolol on AVP-induced cardiomyocyte senescence. Mechanistically, we show that Metoprolol protected cellular senescence by regulating the Sirt1/p53/p21 axis. Our study provides new evidence on the $\beta 1$ blocker Metoprolol in cardiac protection.

Funding This study is funded by the "Innovative research team project of Hainan Natural Science Foundation (2018CXTD349)" and "Social development projects of key R \& D programs in Hainan Province (ZDYF2019134)".

Data Availability The data that support the findings of this study are available from the corresponding author upon reasonable request.

\section{Declarations}

Conflict of interest The authors declare that they have no conflict of interest.

Open Access This article is licensed under a Creative Commons Attribution 4.0 International License, which permits use, sharing, adaptation, distribution and reproduction in any medium or format, as long as you give appropriate credit to the original author(s) and the source, provide a link to the Creative Commons licence, and indicate if changes were made. The images or other third party material in this article are included in the article's Creative Commons licence, unless indicated otherwise in a credit line to the material. If material is not included in the article's Creative Commons licence and your intended use is not permitted by statutory regulation or exceeds the permitted use, you will need to obtain permission directly from the copyright holder. To view a copy of this licence, visit http://creativecommons.org/licenses/by/4.0/.

\section{References}

1. Berk, B. C., Fujiwara, K., \& Lehoux, S. (2007). ECM remodeling in hypertensive heart disease. The Journal of Clinical Investigation, 117, 568-575.

2. Oka, T., \& Komuro, I. (2008). Molecular mechanisms underlying the transition of cardiac hypertrophy to heart failure. Circulation Journal, 72(Suppl A), A13-A16.

3. Manyari, D. E. (1990). Prognostic implications of echocardiographically determined left ventricular mass in the Framingham Heart Study. New England Journal of Medicine, 323, 1706-1707.

4. Sun, R., Zhu, B., Xiong, K., Sun, Y., Shi, D., Chen, L., et al. (2017). Senescence as a novel mechanism involved in beta-adrenergic receptor mediated cardiac hypertrophy. PLoS ONE, 12, e0182668.

5. Dimri, G. P., Lee, X., Basile, G., Acosta, M., Scott, G., Roskelley, C., et al. (1995). A biomarker that identifies senescent human cells in culture and in aging skin in vivo. Proceedings of the National academy of Sciences of the United States of America, 92, 9363-9367.

6. Lopez-Otin, C., Blasco, M. A., Partridge, L., Serrano, M., \& Kroemer, G. (2013). The hallmarks of aging. Cell, 153, 1194-1217.

7. Campisi, J. (2005). Senescent cells, tumor suppression, and organismal aging: Good citizens, bad neighbors. Cell, 120, 513-522.

8. Fountoulaki, K., Dagres, N., \& Iliodromitis, E. K. (2015). Cellular communications in the heart. Cardiac Failure Review, 1, 64-68.

9. Eminler, A. T., Aygun, C., Konduk, T., Kocaman, O., Senturk, O., Celebi, A., et al. (2014). The relationship between resistin and ghrelin levels with fibrosis in nonalcoholic fatty liver disease. Journal of Research in Medical Sciences, 19, 1058-1061.

10. Bergmann, O., Bhardwaj, R. D., Bernard, S., Zdunek, S., BarnabeHeider, F., Walsh, S., et al. (2009). Evidence for cardiomyocyte renewal in humans. Science, 324, 98-102.

11. Maejima, Y., Adachi, S., Ito, H., Hirao, K., \& Isobe, M. (2008). Induction of premature senescence in cardiomyocytes by doxorubicin as a novel mechanism of myocardial damage. Aging Cell, 7, 125-136.

12. Inuzuka, Y., Okuda, J., Kawashima, T., Kato, T., Niizuma, S., Tamaki, Y., et al. (2009). Suppression of phosphoinositide 3-kinase prevents cardiac aging in mice. Circulation, 120, 1695-1703.

13. Mijit, M., Caracciolo, V., Melillo, A., Amicarelli, F., \& Giordano, A. (2020). Role of p53 in the regulation of cellular senescence. Biomolecules, 10(3), 420.

14. Linton, P. J., Gurney, M., Sengstock, D., Mentzer, R. M., Jr., \& Gottlieb, R. A. (2015). This old heart: Cardiac aging and autophagy. Journal of Molecular and Cellular Cardiology, 83, 44-54.

15. Frey, N., \& Olson, E. N. (2003). Cardiac hypertrophy: The good, the bad, and the ugly. Annual Review of Physiology, 65, 45-79.

16. Xing, Y., Niu, T., Wang, W., Li, J., Li, S., Janicki, J. S., et al. (2012). Triterpenoid dihydro-CDDO-trifluoroethyl amide protects against maladaptive cardiac remodeling and dysfunction in mice: a critical role of Nrf2. PLOS ONE, 7, e44899.

17. Kataoka, H. (2021). Arginine vasopressin as an important mediator of fluctuations in the serum creatinine concentration under decongestion treatment in heart failure patients. Circulation Reports, 3(6), 324-332.

18. Hiroyama, M., Wang, S., Aoyagi, T., Oikawa, R., Sanbe, A., Takeo, S., \& Tanoue, A. (2007). Vasopressin promotes cardiomyocyte hypertrophy via the vasopressin V1A receptor in neonatal mice. European Journal of Pharmacology, 559(2-3), 89-97.

19. Benfield, P., Clissold, S. P., \& Brogden, R. N. (1986). Metoprolol. An updated review of its pharmacodynamic and pharmacokinetic properties, and therapeutic efficacy, in hypertension, ischaemic heart disease and related cardiovascular disorders. Drugs, 31(5), 376-429.

20. Papadopoulos, D. P., \& Papademetriou, V. (2009). Metoprolol succinate combination in the treatment of hypertension. Angiology, 60, 608-613.

21. GroupDevereaux, P. S. P. J., Yang, H., Yusuf, S., Guyatt, G., Leslie, K., et al. (2008). Effects of extended-release metoprolol succinate in patients undergoing non-cardiac surgery (POISE trial): A randomised controlled trial. The Lancet, 371, 1839-1847.

22. Wang, M., Lv, Q., Zhao, L., Wang, Y., Luan, Y., Li, Z., et al. (2020). Metoprolol and bisoprolol ameliorate hypertrophy of neonatal rat cardiomyocytes induced by high glucose via the $\mathrm{PKC} /$ NF-kappaB/c-fos signaling pathway. Experimental and Therapeutic Medicine, 19, 871-882.

23. Zhao, J., Lei, Y., Yang, Y., Gao, H., Gai, Z., \& Li, X. (2020). Metoprolol alleviates arginine vasopressin-induced cardiomyocyte hypertrophy by upregulating the AKT1-SERCA2 cascade in H9C2 cells. Cell \& Bioscience, 10, 72. 
24. Zhai, H., Dai, W., \& Wang, Y. (2018). Metoprolol protects cardiomyocytes in rabbit model of heart failure by regulating $\mathrm{Cx} 43$. Experimental and Therapeutic Medicine, 15, 1902-1905.

25. Hou, G., Zhao, H., Teng, H., Li, P., Xu, W., Zhang, J., et al. (2018). N-cadherin attenuates high glucose-induced nucleus pulposus cell senescence through regulation of the ROS/NF-kappaB pathway. Cellular Physiology and Biochemistry, 47, 257-265.

26. Misaka, T., Suzuki, S., Miyata, M., Kobayashi, A., Ishigami, A., Shishido, T., et al. (2013). Senescence marker protein 30 inhibits angiotensin II-induced cardiac hypertrophy and diastolic dysfunction. Biochemical and Biophysical Research Communications, 439, 142-147.

27. Roma-Mateo, C., Seco-Cervera, M., Ibanez-Cabellos, J. S., Perez, G., Berenguer-Pascual, E., Rodriguez, L. R., et al. (2018). Oxidative stress and the epigenetics of cell senescence: Insights from progeroid syndromes. Current Pharmaceutical Design, 24, $4755-4770$.

28. Zhang, G. X., Kimura, S., Nishiyama, A., Shokoji, T., Rahman, M., Yao, L., et al. (2005). Cardiac oxidative stress in acute and chronic isoproterenol-infused rats. Cardiovascular Research, 65, 230-238.

29. Zhang, G. X., Ohmori, K., Nagai, Y., Fujisawa, Y., Nishiyama, A., Abe, Y., et al. (2007). Role of AT1 receptor in isoproterenolinduced cardiac hypertrophy and oxidative stress in mice. Journal of Molecular and Cellular Cardiology, 42, 804-811.

30. Nishida, K., \& Otsu, K. (2016). Autophagy during cardiac remodeling. Journal of Molecular and Cellular Cardiology, 95, 11-18.

31. Li, B., Chi, R. F., Qin, F. Z., \& Guo, X. F. (2016). Distinct changes of myocyte autophagy during myocardial hypertrophy and heart failure: Association with oxidative stress. Experimental Physiology, 101, 1050-1063.

32. Barrett, L. K., Singer, M., \& Clapp, L. H. (2007). Vasopressin: Mechanisms of action on the vasculature in health and in septic shock. Critical Care Medicine, 35, 33-40.

33. Goldsmith, S. R., Francis, G. S., Cowley, A. W., Jr., Levine, T. B., \& Cohn, J. N. (1983). Increased plasma arginine vasopressin levels in patients with congestive heart failure. Journal of the American College of Cardiology, 1, 1385-1390.
34. Nakamura, T., Funayama, H., Yoshimura, A., Tsuruya, Y., Saito, M., Kawakami, M., et al. (2006). Possible vascular role of increased plasma arginine vasopressin in congestive heart failure. International Journal of Cardiology, 106, 191-195.

35. Guarente, L., \& Franklin, H. (2011). Epstein lecture: Sirtuins, aging, and medicine. New England Journal of Medicine, 364, 2235-2244.

36. Imai, S., Armstrong, C. M., Kaeberlein, M., \& Guarente, L. (2000). Transcriptional silencing and longevity protein Sir2 is an NAD-dependent histone deacetylase. Nature, 403, 795-800.

37. Furukawa, A., Tada-Oikawa, S., Kawanishi, S., \& Oikawa, S. (2007). H2O2 accelerates cellular senescence by accumulation of acetylated p53 via decrease in the function of SIRT1 by NAD+ depletion. Cellular Physiology and Biochemistry, 20, 45-54.

38. Ota, H., Akishita, M., Tani, H., Tatefuji, T., Ogawa, S., Iijima, K., et al. (2013). trans-resveratrol in Gnetum gnemon protects against oxidative-stress-induced endothelial senescence. Journal of Natural Products, 76, 1242-1247.

39. Zheng, X., Bair, K. W., Bauer, P., Baumeister, T., Bowman, K. K., Buckmelter, A. J., et al. (2013). Identification of amides derived from $1 \mathrm{H}$-pyrazolo[3,4-b]pyridine-5-carboxylic acid as potent inhibitors of human nicotinamide phosphoribosyltransferase (NAMPT). Bioorganic \& Medicinal Chemistry Letters, 23, 5488-5497.

40. Sano, M., Minamino, T., Toko, H., Miyauchi, H., Orimo, M., Qin, Y., et al. (2007). p53-induced inhibition of Hif-1 causes cardiac dysfunction during pressure overload. Nature, 446, 444-448.

41. Rufini, A., Tucci, P., Celardo, I., \& Melino, G. (2013). Senescence and aging: The critical roles of p53. Oncogene, 32(43), 5129-5143.

42. Kida, Y., \& Goligorsky, M. S. (2016). Sirtuins, cell senescence, and vascular aging. Canadian Journal of Cardiology, 32(5), 634-641.

Publisher's Note Springer Nature remains neutral with regard to jurisdictional claims in published maps and institutional affiliations. 